\title{
An Assessment of the Validity of the Maximum Hardness Principle in Chemical Reactions
}

\author{
Jordi Poater, ${ }^{1}$ Marcel Swart, ${ }^{1,2}$ and Miquel Solà ${ }^{1, *}$ \\ ${ }^{1}$ Institut de Química Computacional \& Dept. de Química, Universitat de Girona, Campus Montilivi, 17071 Girona, Catalonia, \\ Spain.miquel.sola@udg.edu \\ ${ }^{2}$ Institució Catalana de Recerca i Estudis Avançats (ICREA), Pg. Lluis Companys 23, 08010 Barcelona, Catalonia, Spain
}

Dedicated to the Prof. José L. Gázquez as a proof of our admiration for his outstanding contributions to chemistry

Received January 06, 2012; accepted April 26, 2012

\begin{abstract}
We have computationally explored the fulfillment of the Maximum Hardness Principle in chemical reactions. To this end we have selected a well-defined series of 34 exothermic chemical reactions (the so-called BH76 test) and we have calculated the hardness of reactants, transition state, and products. Our results show that for only $18 \%$ of the reactions studied the hardness of the reactants is, at the same time, lower than that of the products and greater than that of the transition state, in agreement with the Maximum Hardness Principle. In most reactions we find that either the transition state has a higher hardness than the reactants or the reactants are harder that the products or both, and, therefore our results show that the Maximum Hardness Principle is disobeyed in most chemical reactions.

Key words: Maximum Hardness Principle, Hardness, Conceptual Density Functional Theory - Chemical Reactivity, HOMO-LUMO gap.
\end{abstract}

\section{Introduction}

In 1987, Pearson stated for the first time the Maximum Hardness Principle (MHP) under the form that "there seems to be a rule of nature that molecules arrange themselves to be as hard as possible" [1]. In the context of the conceptual density functional theory, [2] assuming differentiability of the electronic energy, $E$, with respect to number of electrons, $N$, the hardness is defined as:

$$
\eta=\left(\frac{\partial^{2} E}{\partial N^{2}}\right)_{v(\vec{r})}
$$

and it is a measure of the resistance of the system to a change in the number of electrons.

A formal proof of the MHP based on statistical mechanics and the fluctuation-dissipation theorem was given in 1991 by Parr and Chattaraj [3] under the constraints that $\mu$ and $v(\vec{r})$ must remain constant upon distortion of the molecular structure. There is no single chemical process that satisfies these two severe constraints. However, relaxation of these restrictions seems to be permissible and it has been found that in most cases the MHP still holds even though the chemical and external potentials vary during the analyzed chemical process.

The MHP principle has been successfully applied to the study of molecular vibrations $[4,5]$, internal rotations [6], excited states [7], aromaticity [8], and different types of chemi-
Resumen. Hemos explorado computacionalmente el cumplimiento del Principio de Máxima Dureza en las reacciones químicas. Para este fin se han seleccionado una serie bien definida de 34 reacciones químicas exotérmicas (el denominado test BH76) y se ha calculado la dureza de los reactivos, el estado de transición, y los productos. Nuestros resultados muestran que únicamente en el 18\% de las reacciones estudiadas los reactivos presentan una dureza que es, al mismo tiempo, menor que la de los productos y mayor que la del estado de transición, de acuerdo con el Principio de Máxima Dureza. En la mayoría de las reacciones nos encontramos con que o bien el estado de transición tiene una dureza superior a la de los reactivos o bien los reactivos son más duros que los productos o ambos, y, por tanto, nuestros resultados indican que el Principio de Máxima Dureza no se cumple en la mayoría de las reacciones químicas.

Palabras clave: Principio de máxima dureza, ureza, teoría funcional de densidad conceptual, rectividad química, HOMO-LUMO gap.

cal reactions $[9,10]$. Nontotally symmetric vibrations are particularly interesting because in these nuclear displacements the chemical and external potentials keep approximately constant [4], thus closely following the two conditions of Parr and Chattaraj required for the strict compliance of the maximum hardness principle. In a series of papers [11], some of us have shown that, although these principles are obeyed by most nontotally symmetric vibrations, there are some nontotally symmetric displacements that refuse to comply them. A similar situation holds for chemical reactions. In exothermic chemical reactions, one must expect in the light of the MHP that the hardness decreases along the reaction coordinate from the reactants to the transition state (TS) and increases from the TS to the products. According to the MHP the hardness of the products should be higher than that of the reactants, and this in turn larger than that of the TS. In this context, it is relevant to note that Prof. José L. Gázquez in a series of important studies [12] have found interesting relationships between reaction energies and hardness differences between products and reactants and also between activation energies and changes in hardness when going from reactants to TS [13]. Let us note in passing that the hardness profile computed along the reaction coordinate has been used as a tool to detect spurious stationary points in the potential energy surface [14].

The expected $\eta_{\text {Product }}>\eta_{\text {Reactant }}>\eta_{\text {TS }}$ order is followed by most of the reactions analyzed to date, although there are also many examples in which a breakdown of the MHP is 
observed [15]. In the most frequent situation, the MHP works for the most stable species but the minimum of hardness along the reaction coordinate does not coincide with the TS location [10]. The failure of the MHP is usually attributed to the fact that neither the chemical potential nor the external potential are kept constant along the reaction coordinate. Still, we think it is of interest to know whether the applicability of the MHP to chemical reactions is general and there are just a few exceptions to a general rule or, alternatively, the failure of the MHP in chemical reactions is so common that this principle is not useful in chemical reactivity studies. To our knowledge such a study has not been carried out yet. Thus, the main goal of the present paper is to analyze the validity of the MHP in chemical reactions. To reach our goal we will study a well-defined set of chemical reactions (the so-called $\mathrm{BH} 76$ set [16]) and we will analyze whether the expected $\eta_{\text {Product }}>\eta_{\text {Reactant }}>\eta_{\text {TS }}$ order is followed by these reactions.

\section{Computational details}

The set of reactions chosen for our study is referred as the subset BH76 [16] that is part of the GMTKN30 database [17]. All calculations in this work have been carried out with the BLYP [18] functional employing the large Ahlrichs' type quadruple- $\zeta$ basis set def2-QZVP [19] and with the help of the NWChem 6.0 program [20]. In all cases we have made use of the optimized geometries for reactants, transition states, and products provided by the previous studies [16].

A finite difference approximation to Eq. (1) leads to the following working definition for the hardness:

$$
\eta=I-A,
$$

where $I$ and $A$ are the first vertical ionization potential and the electron affinity of the neutral molecule, respectively. Eq. (2) can be approximated by the energy of the frontier HOMO $\left(\varepsilon_{H}\right)$ and LUMO $\left(\varepsilon_{L}\right)$ molecular orbitals using the Koopmans' theorem $\left(I \approx-\varepsilon_{H}\right.$ and $\left.A \approx-\varepsilon_{L}\right)$ [21]:

$$
\eta=\varepsilon_{L}-\varepsilon_{H}
$$

In DFT the connection between $\varepsilon_{L}$ and $A$ and especially that between $\varepsilon_{H}$ and $I$ is deep-rooted and goes back to the Janak's theorem [22]. How well these frontier eigenvalues approximate the experimental values is another question. In any event, the error in the approximation should be similar for all stationary points along the reaction coordinate and, therefore, trends obtained from Eq. (3) or Eq. (2) are expected to be the same.

For reactions having two reactants or products, we have calculated the hardness as the difference between the lowest LUMO and the highest HOMO of the two isolated reactants. For those reactions in which we obtained a negative value of hardness for the products (i.e. the lowest LUMO is lower in energy than the highest $\mathrm{HOMO}$ as, for instance in the $\mathrm{S}_{\mathrm{N}} 2$ reaction between $\mathrm{F}^{-}+\mathrm{CH}_{3} \mathrm{~F}$ ), we have calculated the corresponding product complex of the reaction and we have considered the hardness of this product complex as the hardness of the products. In addition, in reactions where the energy of separated products was higher than that of the transition state, we have also used the hardness of the corresponding product complex. In the case of the reactants, we have optimized the reactant complex in all cases and used it for the calculation of the hardness, with the only exception of reactions where we have been unable to find a reactant complex. For the geometry optimization of these reactant or product complexes, we have employed the same methodology as for the initial GMTKN30 database [17], thus these geometries have been optimized at the QCISD/MG3 level [23], where the MG3 is the modified G3Large basis set. It is also called the B3LargeMP2 basis set, which is the same as 6-311++G(3d2f,2df,2p) for H-Si [24], but improved for P-Ar [16].

To calculate the chemical potential we have followed the same procedure as that for calculating the hardness but using the following working equation:

$$
\mu=\frac{1}{2}\left(\varepsilon_{L}+\varepsilon_{H}\right)
$$

\section{Results and discussion}

Table 1 collects the results of the hardness of reactants, transition state, and products for the 34 reactions of the $\mathrm{BH} 76$ set analyzed in our study. In all cases, reactants and products have been placed in such a way that the reaction is exothermic (or thermoneutral) and this has forced us to change the direction for some of the reactions in the original $\mathrm{BH} 76$ set [16]. Therefore, in all reactions that are not thermoneutral (29 reactions), the hardness of the products should be higher than that of the reactants according to the MHP. Our results show that this is not the case. In particular only 13 out of 28 (i.e., about $46 \%$, less than $50 \%$ ) of the reactions have a larger hardness for the products than the reactants. On the other hand, according to the MHP, the hardness of the transition state should be lower than that of the reactants and this relation is followed by 18 out of the 34 reactions studied (i.e., about 53\%). As a whole, if we require that at the same time $\eta_{\text {Product }}>\eta_{\text {Reactant }}$ and $\eta_{\text {Reactant }}>$ $\eta_{\mathrm{TS}}$, we find that only 6 of the reactions studied fulfilled the MHP (about 18\%). The rest of the reactions disobey the MHP because either the transition state has a higher hardness than the reactants or the reactants are harder that the products or both.

Of course, these results are not totally unexpected because we know that the constraints that $\mu$ and $v(\vec{r})$ must remain constant along the reaction coordinate are not satisfied by any chemical reaction. However, our results show that changes in chemical potential when going from reactant to product through the transition state are not particularly small for those reactions that follow the MHP. For instance, the $\mathrm{NH}_{2}+\mathrm{C}_{2} \mathrm{H}_{5}$ reaction that partially obeys the MHP and the $\mathrm{CH}_{3}+\mathrm{ClF}$ one that completely disobeys it have a very similar change in chemical potential 
Table 1. The results hardness and chemical potential (both in $\mathrm{eV}$ ) for reactants, transition state, and products for the $\mathrm{BH} 76$ set of reactions under study. All reactions have been written in the direction that they are either exothermic or thermoneutral. The shortest distance (in $\AA$ ) between the reactants in the reactant complex is also given for those reactions having a reactant complex.

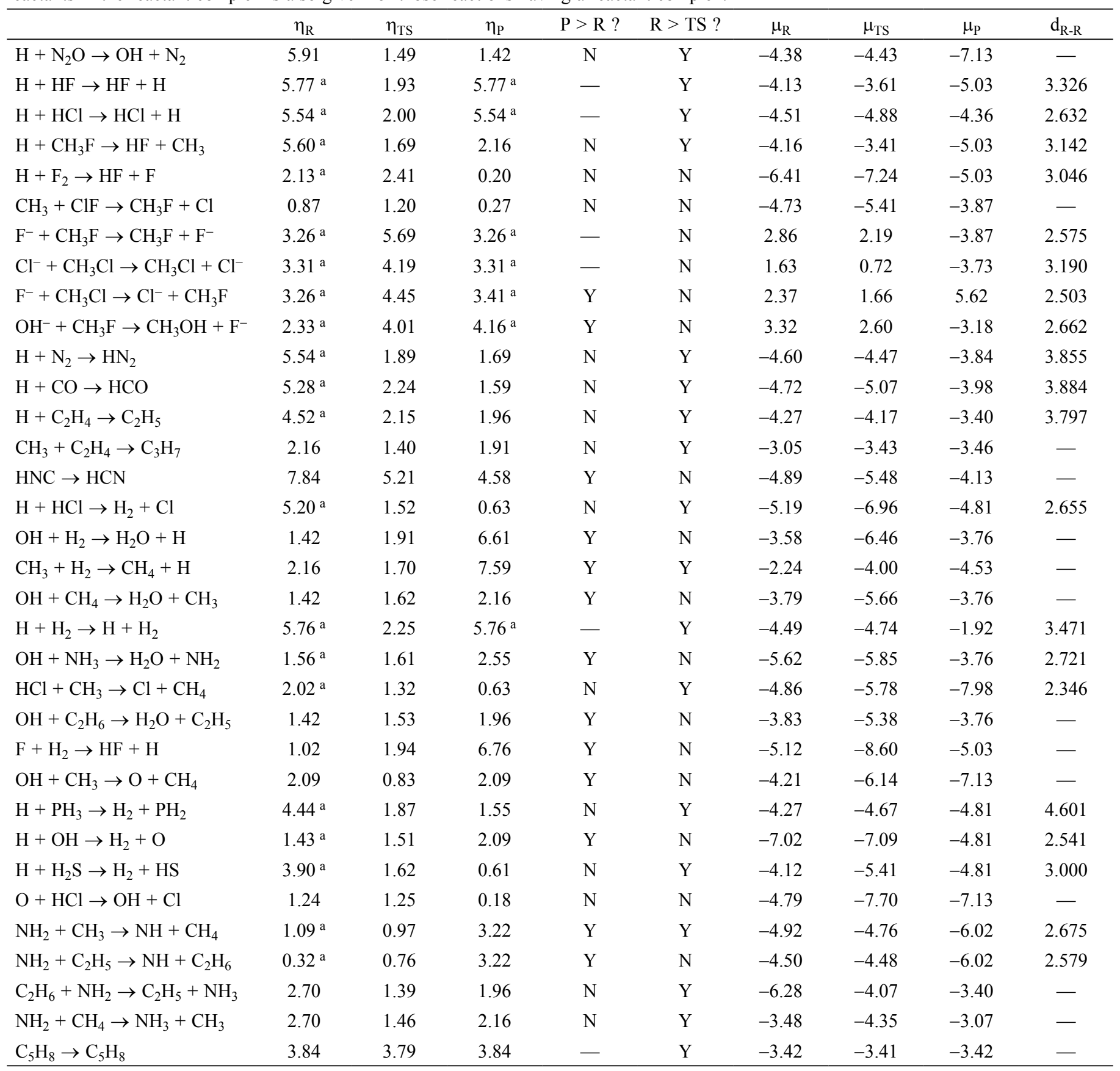

${ }^{a}$ For these compounds, hardness has been calculated from either a reactant or product complex.

(about $1.5 \mathrm{eV}$ between the hardest and the softest species). Although, it is usually said that relaxation of these restrictions seems to be permissible and the MHP holds for most chemical reactions even though the chemical and external potentials vary during the analyzed chemical process, our results show clearly that this is not the case. In fact, we can conclude that it is the other way round: most chemical reactions fail to follow the MHP and, therefore, we discourage the use of this principle to analyze chemical reactivity, except in the few cases where the chemical potential may be kept relatively constant.

Finally, one may wonder what would happen if we use Eq. (2) or other ways to compute the hardness [25] of reactants, transition states, and products. Although we have not checked this aspect, the results obtained using Eq. (3) are so clear that it is very likely that would not dramatically change by varying the procedure used to compute the hardness. Moreover, we 
think that our main conclusion would also not be modified if the number of reactions studied is increased. However, for a general conclusion, it would be necessary to collect and analyze a larger number of reactions.

\section{Conclusions}

In this work, we have calculated the hardness of reactants, transition state, and products for the BH76 test that contains a series of 34 exothermic chemical reactions. Our results show that in most reactions (about $82 \%$ ) either the transition state has a higher hardness than the reactants or the reactants are harder that the products or both, and, therefore our results show that the Maximum Hardness Principle is disobeyed in most chemical reactions. Although for a more general conclusion one should analyze a larger set of reactions, from the results obtained we discourage the use of the Maximum Hardness Principle to analyze chemical reactivity.

\section{Acknowledgments}

We thank the following organizations for financial support: the Ministerio de Ciencia e Innovación (MICINN, project numbers CTQ2011-23156/BQU, CTQ2011-25086/BQU, and Ramón y Cajal contract for JP) and the DIUE of the Generalitat de Catalunya (project numbers 2009SGR637 and 2009SGR528). Support for the research of M. Solà was received through the ICREA Academia 2009 prize for excellence in research funded by the DIUE of the Generalitat de Catalunya. Financial support from MICIN (Ministry of Science and Innovation, Spain) and the FEDER fund (European Fund for Regional Development) was provided.

\section{References}

1. Pearson, R. G. J. Chem. Educ. 1987, 64, 561.

2. De Proft, F.; Geerlings, P. Chem. Rev. 2001, 101, 1451.

3. Parr, R. G.; Chattaraj, P. K. J. Am. Chem. Soc. 1991, 113, 1854.

4. Pearson, R. G.; Palke, W. E. J. Phys. Chem. 1992, 96, 3283.

5. Makov, G. J. Phys. Chem. 1995, 99, 9337; Pal, S.; Naval, N.; Roy, R. J. Phys. Chem. 1993, 97, 4404; Chattaraj, P. K.; Fuentealba, P.; Jaque, P.; Toro-Labbé, A. J. Phys. Chem. A 1999, 103, 9307.

6. Gutiérrez-Oliva, S.; Letelier, J. R.; Toro-Labbé, A. Mol. Phys. 1999, 96, 61; Uchimaru, T.; Chandra, A. K.; Kawahara, S.; Matsumura, K.; Tsuzuki, S.; Mikami, M. J. Phys. Chem. A 2001, 105, 1343; Parthasarathi, R.; Padmanabhan, J.; Subramanian, V.; Maiti, B.; Chattaraj, P. K. J. Phys. Chem. A 2003, 107, 10346; Cadet, J.; Grand, A.; Morell, C.; Letelier, J. R.; Moncada, J. L.; Toro-Labbé, A. J. Phys. Chem. A 2003, 107, 5334; Chattaraj, P. K.; GutiérrezOliva, S.; Jaque, P.; Toro-Labbé, A. Mol. Phys. 2003, 101, 2841; Gutiérrez-Oliva, S.; Toro-Labbé, A. Chem. Phys. Lett. 2004, 383, 435.

7. Chattaraj, P. K.; Poddar, A. J. Phys. Chem. A 1999, 103, 1274; Fuentealba, P.; Simón-Manso, Y.; Chattaraj, P. K. J. Phys. Chem. A 2000, 104, 3185.
8. Zhou, Z. X.; Parr, R. G. J. Am. Chem. Soc. 1989, 111, 7371.

9. Jaque, P.; Toro-Labbé, A. J. Phys. Chem. A 2000, 104, 995; Datta, D. J. Phys. Chem. 1992, 96, 2409; Kar, T.; Scheiner, S. J. Phys. Chem. 1995, 99, 8121; Chattaraj, P. K.; Cedillo, A.; Parr, R. G.; Arnett, E. M. J. Org. Chem. 1995, 60, 4707; Ghanty, T. K.; Ghosh, S. K. J. Phys. Chem. 1996, 100, 12295; Toro-Labbé, A. J. Phys. Chem. A 1999, 103, 4398; Chattaraj, P. K.; Fuentealba, P.; Gómez, B.; Contreras, R. J. Am. Chem. Soc. 2000, 122, 348; Hohm, U. J. Phys. Chem. A 2000, 104, 8418; Jaque, P.; Toro-Labbé, A. J. Chem. Phys. 2002, 117, 3208; Ghanty, T. K.; Ghosh, S. K. J. Phys. Chem. A 2002, 106, 4200; Pérez, P.; Toro-Labbé, A. J. Phys. Chem. A 2000, 104, 1557; Chattaraj, P. K.; Pérez, P.; Zevallos, J.; Toro-Labbé, A. J. Phys. Chem. A 2001, 105, 4272; Chandra, A. K.; Nguyen, M. T. J. Phys. Chem. A 1998, 102, 6181.

10. Mineva T.; Sicilia, E.; Russo, N. J. Am. Chem. Soc. 1998, 120, 9053.

11. Torrent-Sucarrat, M.; Luis, J. M.; Duran, M.; Solà, M. J. Am. Chem. Soc. 2001, 123, 7951; Torrent-Sucarrat, M.; Duran, M.; Luis, J. M.; Solà, M. J. Phys. Chem. A 2005, 109, 615; Torrent-Sucarrat, M.; Luis, J. M.; Duran, M.; Solà, M. J. Chem. Phys. 2002, 117, 10651; Torrent-Sucarrat, M.; Luis, J. M.; Solà, M. Chem. Eur. J. 2005, 11, 6024; Blancafort, L.; Torrent-Sucarrat, M.; Luis, J. M.; Duran, M.; Solà, M. J. Phys. Chem. A 2003, 107, 7337; Torrent-Sucarrat, M.; Blancafort, L.; Duran, M.; Luis, J. M.; Solà, M. In Theoretical Aspects of Chemical Reactivity; Toro-Labbé, A., Ed.; Elsevier: Amsterdam, 2007; Vol. 19, p 31.

12. Gázquez, J. L. J. Phys. Chem. A 1997, 101, 9464; Gázquez, J. L. J. Phys. Chem. A 1997, 101, 8967; Gázquez, J. L.; Martínez, A.; Méndez, F. J. Phys. Chem. 1993, 97, 4059; Gázquez, J. L. In Structure and Bonding; Springer-Verlag: Berlin, 1993; Vol. 80, p 27.

13. Zhou, Z.; Parr, R. G. J. Am. Chem. Soc. 1990, 112, 5720.

14. Torrent-Sucarrat, M.; Luis, J. M.; Duran, M.; Solà, M. J. Chem. Phys. 2004, 120, 10914; Torrent-Sucarrat, M.; Luis, J. M.; Duran, M.; Solà, M. J. Chem. Sci. 2005, 117, 549.

15. Kar, T.; Scheiner, S. J. Phys. Chem. 1995, 99, 8121; Gómez, B.; Fuentealba, P.; Contreras, R. Theor. Chem. Acc. 2003, 110, 421; Chandra, A. K.; Uchimaru, T. J. Phys. Chem. A 2001, 105, 3578; Nguyen, L. T.; Le, T. N.; De Proft, F.; Chandra, A. K.; Langenaeker, W.; Nguyen, M. T.; Geerlings, P. J. Am. Chem. Soc. 1999, 121, 5992; Torrent-Sucarrat, M.; Toro-Labbé, A.; Solà, M. J. Phys. Chem. A 2006, 110, 8901; Elango, M.; Parthasarathi, R.; Subramanian, V.; Sakar, U.; Chattaraj, P. K. J. Mol. Struct. (Theochem) 2005, 723, 43; Herrera, B.; Toro-Labbé, A. J. Phys. Chem. A 2004, 2004, 1830.

16. Zhao, Y.; Lynch, B. J.; Truhlar, D. G. J. Phys. Chem. A 2004, 108, 2715; Zhao, Y.; González-García, N.; Truhlar, D. G. J. Phys. Chem. A 2005, 109, 2012.

17. Goerigk, L.; Grimme, S. J. Chem. Theor. Comput. 2010, 7, 291; Goerigk, L.; Grimme, S. Phys. Chem. Chem. Phys. 2011, 13, 6670.

18. Lee, C.; Yang, W.; Parr, R. G. Phys. Rev. B 1988, 37, 785; Miehlich, B.; Savin, A.; Stoll, H.; Preuss, H. Chem. Phys. Lett. 1989, $157,200$.

19. Weigend, F.; Ahlrichs, R. Phys. Chem. Chem. Phys. 2005, 7, 3297.

20. Valiev, M.; Bylaska, E. J.; Govind, N.; Kowalski, K.; Straatsma, T. P.; van Dam, H. J. J.; Wang, D.; Nieplocha, J.; Apra, E.; Windus, T. L.; de Jong, W. A. Comput. Phys. Commun. 2010, 181, 1477.

21. Koopmans, T. Physica (Utrecht) 1933, 1, 104.

22. Janak, J. F. Phys. Rev. B 1978, 18, 7165; Gritsenko, O. V.; Baerends, E. J. J. Chem. Phys. 2002, 117, 9154; Cohen, A. J.; MoriSánchez, P.; Yang, W. Chem. Rev. 2012, 112, 289; Parr, R. G.; Yang, W. Density-functional theory of atoms and molecules; Oxford Univesity Press: New York, 1989. 
23. Pople, J. A.; Head-Gordon, M.; Raghavachari, K. J. Chem. Phys. 1987, 87, 5968.

24. Frisch, M. J.; Pople, J. A.; Binkley, J. S. J. Chem. Phys. 1984, 80, 3265 .
25. Torrent-Sucarrat, M.; Duran, M.; Solà, M. J. Phys. Chem. A 2002, 106, 4632; Torrent-Sucarrat, M.; Luis, J. M.; Duran, M.; Solà, M. J. Mol. Struct. (Theochem) 2005, 727, 139; Torrent-Sucarrat, M.; Salvador, P.; Geerlings, P.; Solà, M. J. Comput. Chem. 2007, 28, 574. 